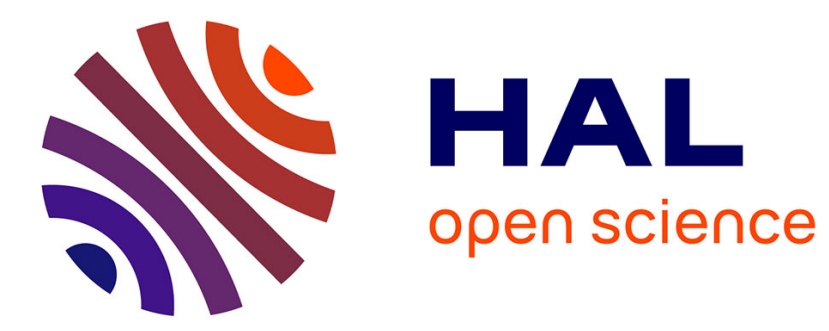

\title{
Evolution and regulation of complex life cycles: a brown algal perspective
}

J Mark Cock, Olivier Godfroy, Nicolas N. Macaisne, Akira F Peters, Susana

Coelho

\section{- To cite this version:}

J Mark Cock, Olivier Godfroy, Nicolas N. Macaisne, Akira F Peters, Susana Coelho. Evolution and regulation of complex life cycles: a brown algal perspective. Current Opinion in Plant Biology, 2014, 17, pp.1-6. 10.1016/j.pbi.2013.09.004 . hal-01806434

\section{HAL Id: hal-01806434 \\ https://hal.science/hal-01806434}

Submitted on 6 Jun 2018

HAL is a multi-disciplinary open access archive for the deposit and dissemination of scientific research documents, whether they are published or not. The documents may come from teaching and research institutions in France or abroad, or from public or private research centers.
L'archive ouverte pluridisciplinaire HAL, est destinée au dépôt et à la diffusion de documents scientifiques de niveau recherche, publiés ou non, émanant des établissements d'enseignement et de recherche français ou étrangers, des laboratoires publics ou privés. 


\title{
Evolution and regulation of complex life cycles: a brown algal perspective
}

J. Mark Cock ${ }^{1,2}$, Olivier Godfroy ${ }^{1,2}$, Nicolas Macaisne ${ }^{1,2}$, Akira F. Peters ${ }^{3}$ and Susana M. Coelho ${ }^{1,2}$

\author{
Addresses \\ ${ }^{1}$ UPMC Univ. Paris 06, The Marine Plants and Biomolecules Laboratory, UMR 7139, Station \\ Biologique de Roscoff, Place Georges Teissier, BP74, 29682 Roscoff Cedex, France. \\ 2 CNRS, UMR 7139, Laboratoire International Associé Dispersal and Adaptation in Marine \\ Species, Station Biologique de Roscoff, Place Georges Teissier, BP74, 29682 Roscoff Cedex, \\ France. \\ ${ }^{3}$ Bezhin Rosko, 29250, Santec, France
}

Corresponding author: Cock, J. Mark

(cock@sb-roscoff.fr)

\section{Short title}

Brown algal life cycle regulation

\section{Highlights}

- Brown algae exhibit diverse life cycles

- Brown algal life cycle mutants link life cycle progression with development

- Green lineage studies implicate TALE homeodomain and PRC2 proteins as regulators

- Some life cycle regulators may be ancient, predating multicellularity

\begin{abstract}
The life cycle of an organism is one of its fundamental features, influencing many aspects of its biology. The brown algae exhibit a diverse range of life cycles indicating that transitions between life cycle types may have been key adaptive events in the evolution of this group. Life cycle mutants, identified in the model organism Ectocarpus, are providing information about how life cycle progression is regulated at the molecular level in brown algae. We explore some of the implications of the phenotypes of the life cycle mutants described to date and draw comparisons with recent insights into life cycle regulation in the green lineage. Given the importance of coordinating growth and development with life cycle progression, we suggest that the co-option of ancient life cycle regulators to control key developmental events may be a common feature in diverse groups of multicellular eukaryotes.
\end{abstract}

\section{Introduction}

Eukaryotic organisms exhibit a broad range of different life cycles [1]. Reproduction can be sexual or asexual and a single life cycle often involves a combination of these two reproductive strategies. Asexual reproduction can occur via a variety of different processes (asexual spores, fragmentation, parthenogenesis, etc.) and sexual life cycles also come in several flavours, the major types being haploid, diploid and haploid-diploid cycles (Figure 1). For multicellular, photosynthetic organisms with haploid-diploid life cycles, the diploid phase generally corresponds to the sporophyte (spore-producing) generation, whereas the haploid phase is the gametophyte (gamete-producing) generation. As we shall see, however, the correspondence between the sporophyte and gametophyte generations and ploidy is not absolute and mutations or 
natural variations that uncouple ploidy and life cycle generation can provide important insights into life cycle regulation and function.

\section{Theoretical advantages of different life cycle strategies}

A wealth of information is available about life cycle variation across the eukaryotic tree but important, basic questions remain to be answered, in particular with regard to the adaptive benefits of each type of life cycle. Several possible advantages have been proposed for both haploid and diploid life cycles, based for example on factors such as purging or masking of deleterious mutations in haploids and diploids, respectively [1]. The evolutionary stability of haploid-diploid life cycles cannot be explained by these factors but alternative hypotheses have been proposed, such as the suggestion that the different generations of the life cycle are adapted to different niches, allowing these species to survive in a fluctuating environment [2,3]. Here differences between niches is meant in a broad sense, and may include both abiotic (e.g. seasonal) and biotic (e.g. pathogens and other symbiotes) factors. These various hypotheses provide a framework for future research but, to date, very little experimental work has been carried out to test them.

\section{Genetic regulation of life cycle progression}

Another aspect that is still very poorly understood concerns the mechanisms that regulate life cycle progression. A better understanding of these mechanisms will be essential to address broader questions concerning life cycle evolution and function. Several model systems are being employed to explore the molecular bases of life cycle regulation, but brown algal models are particularly interesting for a number of reasons. As a group, the brown algae or Phaeophyceae exhibit many different types of life cycle [4]. These range from the diploid life cycles of fucoid algae such as Fucus or Sylvetia, with just one life cycle generation, to the isomorphic haploiddiploid life cycles of the Dictyotales, the Ishigeales and some members of the Sphacelariales and Ectocarpales, where there are two, morphologically similar generations during the life cycle. Between these two extremes, there are species that have haploid-diploid life cycles with more or less marked differences between the two generations, in terms of size and morphology, with either the sporophyte or the gametophyte generation being dominant in terms of size. Kelps such as Laminaria, for example, have haploid-diploid life cycles with a large, macroscopic sporophyte generation and a microscopic gametophyte generation. Kelp life cycles are therefore similar to those of angiosperms, except that the gametophyte is free-living.

When the different types of brown algal life cycle are mapped onto a phylogenetic tree, the distribution pattern suggests that there has been considerable switching between different life cycle strategies during the evolution of this group (Figure 2) [5]. The brown algae therefore represent a particularly interesting group to explore life cycle function in relation to an organism's ecology. The brown algae are also one of only a small number of eukaryotic groups that have evolved complex multicellularity $\left[6,7^{*}, 8^{*}\right]$ and therefore potentially allow access to interactions between the life cycle and developmental processes.

\section{Regulation of life cycle progression in the model brown alga Ectocarpus}

The model brown alga Ectocarpus is being used in studies aimed at understanding how life cycle progression is regulated at the molecular level. Ectocarpus has a number of features that make it particularly well adapted to address this question [1,9*]. The haploid-diploid life cycle of this species involves an alternation between sporophyte and gametophyte generations with similar, but not identical, morphologies. Both are small filamentous organisms that can grow up to 
several centimetres in length but there are marked morphological differences, particularly during early development [10]. In both cases, the initial cell germinates by producing two germ tubes, but there are then significant differences in cell fate. In the gametophyte, the first cell division is asymmetrical, producing a root-like structure (the rhizoid) and an "upright filament", which grows up from the substratum and forms the branched thallus that bears the sexual structures (gametangia). In the sporophyte, the first cell division is symmetrical in that it produces the first two cells of a firmly attached basal filament, which grows and branches to produce a dense basal structure. It is only when this basal structure is established that erect filaments differentiate and grow up into the medium where they produce the sporophyte sexual structures (meio-sporangia). Importantly, both the sporophyte and the gametophyte are free-living, developing from initial cells that are released into the surrounding medium. Together, these features have been exploited to screen for Ectocarpus mutants that exhibit aberrant implementation of the sporophyte and gametophyte developmental programs. Two mutants of this type have been described to date, the immediate upright (imm) mutant [10], which exhibits partial conversion of the sporophyte generation into a gametophyte during early development, and the ouroboros (oro) mutant [11**], in which the sporophyte generation is converted into a fully functional gametophyte.

The switching between life cycle generations in the imm and oro mutants does not involve changes in ploidy. Consequently, one of the surprising conclusions that can be drawn from the existence of these mutants is that life cycle generation (whether an organism develops as a sporophyte or a gametophyte) is not strictly correlated with ploidy. This conclusion is supported by several other observations in wild type strains, including the ability of Ectocarpus gametes, which have failed to fuse with a gamete of the opposite sex, to develop autonomously to produce haploid partheno-sporophytes [12]. Similarly, it has recently been shown that sporophytes produce a diffusible factor that induces haploid meio-spores (which normally develop as gametophytes) to adopt the sporophyte developmental program [13*]. Sporophytes can therefore be haploid under some conditions and, conversely, it is also possible to obtain diploid gametophytes by crossing two strains carrying the recessive oro mutation [11]. Taken together, these various observations indicate that changes in ploidy are better viewed as a consequence of life cycle progression than as the determinant of life cycle generation identity.

\section{Molecules that regulate life cycle transitions: insights from the green lineage}

Based on the observed phenotypes, the genes affected by the imm and oro mutations appear to act as master regulators of the gametophyte to sporophyte transition. This is consistent with the broad transcriptome modifications observed in the presence of the two mutations $[10,11]$. Ongoing efforts to identify and characterise the $O R O$ and IMM genes are expected to provide insight into the molecular system that regulates this process. In the meantime, work carried out with model organisms from the green lineage have provided some clues as to the types of molecular components that we may expect to find. In the haploid life cycle of the unicellular, green alga Chlamydomonas, gamete fusion leads to the induction of a number of processes associated with the short diploid phase of the life cycle, including the onset of meiosis [14]. This process is controlled by a heterodimeric homeodomain transcription factor, which is formed when its two components, Gsm1 and Gsp1 (carried by the minus and plus gametes respectively), are brought together in the zygote [15]. It is possible that the oro mutation affects a similar process, whose role is to detect the cell fusion event that forms the zygote, signalling the transition to the sporophyte phase of the life cycle. This type of system may be widespread across the eukaryotes. Indeed, it has been suggested that one of the major functions of mating type systems, in general, may be to act as detectors of the haploid to diploid transition that occurs when a zygote is formed by gamete fusion [16**]. It is noteworthy that mating type loci 
commonly encode transcription factors or molecules involved in the regulation of transcription factors.

Recent work indicates that a similar system to that described in Chamydomonas may be operating in the multicellular streptophyte moss Physcomitrella patens. In moss plants with mutations in two transcription factor genes, $M K N 1$ and $M K N 6$, the sporophyte generation develops as a fully functional diploid gametophyte [17**]. The parallel between the Chlamydomonas and moss systems extends to the molecular level because Chlamydomonas Gsm1 and moss MKN1 and MKN6 all encode three-amino acid loop extension (TALE) homeodomain proteins of the knotted-like homeobox (KNOX) class. Moreover, the P. patens genome is also predicted to encode four proteins similar to Gsp1, which is a BEL-class TALE homeodomain transcription factor. Two of the moss BEL-class genes are expressed predominantly in sporophytes, but it is not yet know whether these proteins play a role in regulating the gametophyte to sporophyte transition [17**]. The similarities between the Chlamydomonas and moss systems suggest that they may be derived from common ancestral system that has been conserved over the long period of evolutionary time (approximately 1000 My) that separates these two lineages. As a family, the TALE homeodomain protein family is very ancient, dating back to the last common eukaryote ancestor [18], and three TALE homeobox (i.e. homeodomain-encoding) genes have been identified in the Ectocarpus genome.

\section{A genetic link between life cycle progression and development}

A common feature of the Ectocarpus oro and the moss $m k n 1 / m k n 6$ mutations is that they can be interpreted as affecting both life cycle progression and key developmental processes. Indeed, the oro mutant has been proposed to represent a new class of homeotic mutation, causing switching between developmental programs, not at the organ or tissue level, but at the level of the whole organism (i.e. between the sporophyte and gametophyte developmental programs; [11**]). The moss $m k n 1 / m k n 6$ mutant would also fall into this class.

By providing a link between life cycle and developmental regulation, the moss and Ectocarpus life cycle mutants suggest new ways of thinking about how these two processes are coordinated. Given the spectacular complexity of developmental processes in complex multicellular organisms, it is tempting to think of developmental processes as structuring the life of an organism, providing the context for life cycle events such as gamete production and zygote formation. From an evolutionary point of view, however, it makes more sense to think of developmental processes as elaborations on an underlying program that initially regulated life cycle progression. This is because complex multicellular organisms such as land plants and brown algae evolved from unicellular ancestors, with multicellularity presumably having emerged as a means of optimising reproductive potential within the life cycle by improving parameters such as production and/or dispersal of gametes and spores, mating success and survival between key life cycle stages. From this point of view, the relationship between developmental programs and life cycle regulation can be seen to be analogous to computer programs designed to function within the context of an underlying operating system. With this model in mind, we should not be surprised when major life cycle regulatory genes such as $O R O$ and $M K N 1 / M K N 6$ also turn out to be key developmental regulators. Another interesting consequence is that some master regulators of developmental processes may have existed before the emergence of developmental processes that they regulate, having carried out life-cycle-related regulatory roles in unicellular ancestral species. This may have been the case for the ancestors of the moss proteins MKN1/MKN6 for example. 
In the green lineage, polycomb repressive complex 2 (PRC2), which regulates gene expression by methylating histone $\mathrm{H} 3$, has also been implicated in the regulation of the gametophyte to sporophyte transition. In Arabidopsis, transitions from gametophyte cell fate to produce endosperm or embryo-like structures have been observed in several mutants affect in PRC2 function [19-24], including one case where the gametophyte-to-sporophyte transition was shown to involve an induction of sporophyte generation marker genes [25]. Similarly in the moss $P$. patens, fertilization-independent production of sporophyte-like bodies on side branches of gametophytic protonema filaments was observed following independent mutations of two PRC2 complex genes, PHYSCOMITRELLA PATENS CURLY LEAF and PHYSCOMITRELLA PATENS FERTILIZATION INDEPENDENT ENDOSPERM [26,27]. In both cases the sporophyte-like bodies expressed sporophyte generation marker genes. Taken together, these studies suggest a role for the PRC2 complex in repressing the sporophyte developmental pathway during the gametophyte generation of the life cycle. Interestingly, recent work has shown that PRC2 is required for the maintenance of oocyte cell fate in Drosophila, ablation of the complex leading to de-differention of the oocyte and its entry into the endocycle along with the other nurse cells [28]. Although it is probable that life cycle transitions in brown algae also involve chromatin remodelling, it is unlikely that PRC2 is involved because the Ectocarpus genome encodes none of the PRC2 proteins apart from a putative MULTICOPY SUPPRESSOR OF IRA 1 homologue (and there is evidence that this protein functions in several different chromatin modifying complexes; [23,29-32]).

\section{Conclusion}

Brown algae represent interesting models to study life cycle evolution and genetic mutants such as oro and $\mathrm{imm}$ are expected to provide access to key regulators of life cycle progression in this lineage. Based on work on model systems from the green lineage, involvement of homeodomain transcription factors and chromatin modification in life cycle regulation are emerging as central themes. These regulatory systems appear to be very ancient, in some cases probably predating the emergence of multicellularity. Given that the lineage that gave rise to the brown algae diverged from the green lineage well over a billion years ago and that the brown algae have derived their own version of complex multicellular development, it will be interesting to see whether analogous mechanisms regulate brown algal life cycles.

The life cycle of an organism is one of its most elemental features, underpinning a broad range of phenomena including developmental processes, reproductive fitness, mode of dispersal and adaptation to the local environment. It is only very recently, however, that information about the molecular components that regulate life cycle transitions has started to emerge and much still remains to be done in this domain. In particular, studies have so far focused on the gametophyte to sporophyte transition, and regulation of the sporophyte to gametophyte transition still remains something of a mystery. Meiosis is clearly the central step in this transition and it is likely that there is a link between the mechanisms that regulate meiosis and those that control initiation of the gametophyte program.

\section{Conflict of interest}

The authors have no conflict of interest. 
We would like to thank Thomas Silberfeld for providing the species tree used to construct Figure 2. Work on Ectocarpus was supported by the Centre National de Recherche Scientifique, the University Pierre and Marie Curie, the European network of excellence Marine Genomics, the Interreg program France (Channel)-England (project Marinexus) and the Agence Nationale de la Recherche (project Bi-cycle).

\section{Figure 1}

Major types of eukaryotic sexual life cycle. Variation between sexual cycles corresponds principally to differences in the relative positioning of meiosis and gamete fusion (syngamy). When meiosis produces gametes that directly fuse to produce a zygote, the organism spends almost its entire life cycle in the diploid phase (a diploid life cycle), whereas if meiosis directly follows gamete fusion, it is the haploid phase that dominates (a haploid life cycle). When meiosis and gamete fusion occur at different points in the life cycle, there is an alternation between haploid and diploid stages (a haploid-diploid life cycle). The haploid-diploid class actually includes a range of different life cycles in which either the diploid or the haploid phase may be dominant (in multicellular organisms this corresponds to differences in size, and often complexity, between the two phases of the life cycle). Haploid and diploid life cycles can be seen as extremes of this range in which no mitotic divisions occur in one of the two phases. Note also that some red algae have more complex, so-called triphasic life cycles, with one haploid and two diploid phases [33].

\section{Figure 2}

The brown algae exhibit a broad range of life cycle types. Life cycle type has been mapped onto the phylogenetic tree of the brown algae (Phaeophyceae) described in [5]. See [5] for the names of the species in each order.

\section{References and recommended reading}

Papers of particular interest, published within the period of review, have been highlighted as:

* of special interest

** of outstanding interest

1. Coelho S, Peters A, Charrier B, Roze D, Destombe C, Valero M, Cock J: Complex life cycles of multicellular eukaryotes: new approaches based on the use of model organisms. Gene 2007, 406:152-170.

2. Hughes JS, Otto SP: Ecology and the evolution of biphasic life cycles. Am Nat 1999, 154:306-320.

3. Stebbins GL, Hill GJC: Did Multicellular Plants Invade the Land? Am Nat 1980, 115:342353.

4. de Reviers B: Biologie et phylogénie des algues. Tome 2: Belin; 2003.

5. Silberfeld T, Leigh JW, Verbruggen H, Cruaud C, de Reviers B, Rousseau F: A multi-locus time-calibrated phylogeny of the brown algae (Heterokonta, Ochrophyta, Phaeophyceae): Investigating the evolutionary nature of the "brown algal crown radiation". Mol Phylogenet Evol 2010, 56:659-674. 
6. Cock JM, Sterck L, Rouzé P, Scornet D, Allen AE, Amoutzias G, Anthouard V, Artiguenave F, Aury J, Badger J, et al.: The Ectocarpus genome and the independent evolution of multicellularity in brown algae. Nature 2010, 465:617-621.

\section{*7. Knoll AH: The Multiple Origins of Complex Multicellularity. Annu Rev Earth Planet Sci 2011, 39:217-239.}

The author compares the rare transitions to complex multicellularity within the eukaryotes with the more numerous transitions to simple multicellularity and proposes that the former share many common features. Only six clades are considered to have evolved complex multicellularity (animals, land plants, two groups of fungi, red algae, and brown algae). Common features shared by all of these six clades include the emergence of gene families involved in cell-cell adhesion and communication and the development of mechanisms to circumvent the problem of diffusion of oxygen and nutrients into multiple cell layers. See also [8].

\section{*8. Niklas KJ, Newman SA: The origins of multicellular organisms. Evol Dev 2013, 15:41-} 52.

The authors discuss both similarities and differences between independent transitions to multicellularity in different eukaryotic groups and propose series of morphological steps leading from unicellular states to multicellular states of different complexities. The importance of cell-tocell adhesion and cell-to-cell communication, cooperation and specialization is underlined. See also [7].

*9. Coelho SM, Scornet D, Rousvoal S, Peters N, Dartevelle L, Peters AF, Cock JM:

Ectocarpus: A model organism for the brown algae. Cold Spring Harbor Protoc 2012, 2012:193-198.

This article, together with a series of associated protocols, provides a concise overview of the emergence of Ectocarpus as a model system for the brown algae and describes some of the genetic and genomic resources that have been developed for this organism. The brown algae, being members of the Stramenopiles, are very distantly related to well-studied animal and green plant models and the authors stress the importance of developing a effective model organism to explore the unusual biological features of this group of seaweeds.

10. Peters AF, Scornet D, Ratin M, Charrier B, Monnier A, Merrien Y, Corre E, Coelho SM, Cock JM: Life-cycle-generation-specific developmental processes are modified in the immediate upright mutant of the brown alga Ectocarpus siliculosus. Development 2008, 135:1503-1512.

**11. Coelho SM, Godfroy O, Arun A, Le Corguillé G, Peters AF, Cock JM: OUROBOROS is a master regulator of the gametophyte to sporophyte life cycle transition in the brown alga Ectocarpus. Proc Natl Acad Sci U S A 2011, 108:11518-11523.

The Ectocarpus mutant ouroboros exhibits a modified life cycle, constantly reiterating the gametophyte generation rather than alternating between gametophyte and sporophyte.

Microarray analysis indicated that OUROBOROS acts both to induce the sporophyte developmental program and to repress genes that are normally expressed during the gametophyte generation. A large number of genes exhibited alterations in transcript abundance in the presence of the ouroboros mutation, consistent with OUROBOROS acting as a master regulator of the gametophyte-sporophyte switch. Genetic analysis of the ouroboros mutation provided a striking illustration that life cycle generation is not determined strictly by ploidy; diploid individuals homozygous for this mutation developed as gametophytes. 
12. Müller DG: Generationswechsel, Kernphasenwechsel und Sexualität der Braunalge Ectocarpus siliculosus im Kulturversuch. Planta 1967, 75:39-54.

\section{*13. Arun A, Peters NT, Scornet D, Peters AF, Cock JM, Coelho SM: Non-cell autonomous regulation of life cycle transitions in the model brown alga Ectocarpus. New Phytol 2013, 197:503-510.}

It has been known for many years that, in some strains of Ectocarpus, a small proportion of meio-spores develop as sporophytes rather than gametophytes, a phenomenon known as heteroblasty. This study showed that sporophytes produce a diffusible factor that can induce meio-spores of a strain that does not normally exhibit heteroblasty to develop as sporophytes. The diffusible factor is only active on cells that lack a cell wall (meio-spores or gametophytederived protoplasts) and requires the presence of a functional OUROBOROS gene. The characterisation of this diffusible factor provides a further illustration of how the alternation between the gametophyte and sporophyte generations can be uncoupled from changes in ploidy due to life cycle progression.

14. Zhao H, Lu M, Singh R, Snell WJ: Ectopic expression of a Chlamydomonas mt+-specific homeodomain protein in mt- gametes initiates zygote development without gamete fusion. Genes Dev 2001, 15:2767-2777.

\section{Lee JH, Lin H, Joo S, Goodenough U: Early sexual origins of homeoprotein heterodimerization and evolution of the plant KNOX/BELL family. Cell 2008, 133:829-840.}

**16. Perrin N: What uses are mating types? The "developmental switch" model. Evolution 2012, 66:947-956.

The author argues that data on mating type systems from diverse taxa are not consistent with many of the current hypotheses that address the functions of these systems, such as control of organelle transmission or prevention of inbreeding or same-clone mating. He suggests that mating types have evolved primarily to switch on developmental programs and specific cellular processes at the appropriate moment during the life cycle. This hypothesis is consistent with the role of the Chlamydomonas mating type-dependent factor Gsm1 in initiating the "diploid" program in this species and it provides a pertinent theoretical context for exploring the relationship between life cycle progression and developmental regulation in multicellular eukaryotic organisms.

**17. Sakakibara K, Ando S, Yip HK, Tamada Y, Hiwatashi Y, Murata T, Deguchi H, Hasebe M, Bowman JL: KNOX2 genes regulate the haploid-to-diploid morphological transition in land plants. Science 2013, 339:1067-1070.

Deletion of two class 2 KNOTTED1-LIKE HOMEOBOX (KNOX) genes from the genome of the moss Physcomitrella patens caused diploid embryos to develop as gametophytes rather than sporophytes. The phenotype of this double mutant is therefore exactly equivalent to that of the Ectocarpus ouroboros mutant.

18. Derelle R, Lopez P, Le Guyader H, Manuel M: Homeodomain proteins belong to the ancestral molecular toolkit of eukaryotes. Evol Dev 2007, 9:212-219.

19. Chaudhury AM, Ming L, Miller C, Craig S, Dennis ES, Peacock WJ: Fertilizationindependent seed development in Arabidopsis thaliana. Proc Natl Acad Sci U S A 1997, 94:4223-4228. 
20. Köhler C, Hennig L, Bouveret R, Gheyselinck J, Grossniklaus U, Gruissem W: Arabidopsis MSI1 is a component of the MEA/FIE Polycomb group complex and required for seed development. $E M B O J$ 2003, 22:4804-4814.

21. Ohad N, Margossian L, Hsu YC, Williams C, Repetti P, Fischer RL: A mutation that allows endosperm development without fertilization. Proc Natl Acad Sci U S A 1996, 93:5319-5324.

22. Ohad N, Yadegari R, Margossian L, Hannon M, Michaeli D, Harada JJ, Goldberg RB, Fischer RL: Mutations in FIE, a WD polycomb group gene, allow endosperm development without fertilization. Plant Cell 1999, 11:407-416.

23. Ebel C, Mariconti L, Gruissem W: Plant retinoblastoma homologues control nuclear proliferation in the female gametophyte. Nature 2004, 429:776-780.

24. Guitton AE, Page DR, Chambrier P, Lionnet C, Faure JE, Grossniklaus U, Berger F: Identification of new members of Fertilisation Independent Seed Polycomb Group pathway involved in the control of seed development in Arabidopsis thaliana. Development 2004, 131:2971-2981.

25. Guitton AE, Berger F: Loss of function of MULTICOPY SUPPRESSOR OF IRA 1 produces nonviable parthenogenetic embryos in Arabidopsis. Curr Biol 2005, 15:750-754.

26. Okano Y, Aono N, Hiwatashi Y, Murata T, Nishiyama T, Ishikawa T, Kubo M, Hasebe M: A polycomb repressive complex 2 gene regulates apogamy and gives evolutionary insights into early land plant evolution. Proc Natl Acad Sci U S A 2009, 106:1632116326.

27. Mosquna A, Katz A, Decker EL, Rensing SA, Reski R, Ohad N: Regulation of stem cell maintenance by the Polycomb protein FIE has been conserved during land plant evolution. Development 2009, 136:2433-2444.

28. Iovino N, Ciabrelli F, Cavalli G: PRC2 Controls Drosophila Oocyte Cell Fate by Repressing Cell Cycle Genes. Dev Cell 2013.

29. Hennig L, Bouveret R, Gruissem W: MSI1-like proteins: an escort service for chromatin assembly and remodeling complexes. Trends Cell Biol 2005, 15:295-302.

30. Kaya H, Shibahara KI, Taoka KI, Iwabuchi M, Stillman B, Araki T: FASCIATA genes for chromatin assembly factor-1 in Arabidopsis maintain the cellular organization of apical meristems. Cell 2001, 104:131-142.

31. Jullien PE, Mosquna A, Ingouff M, Sakata T, Ohad N, Berger F: Retinoblastoma and its binding partner MSI1 control imprinting in Arabidopsis. PLoS Biol 2008, 6:e194.

32. Ach RA, Taranto P, Gruissem W: A conserved family of WD-40 proteins binds to the retinoblastoma protein in both plants and animals. Plant Cell 1997, 9:1595-1606. 
33. Yamanouchi S: The life history of Polysiphonia violacea. Bot Gaz 1906, 42:401-449. 
Diploid life cycle
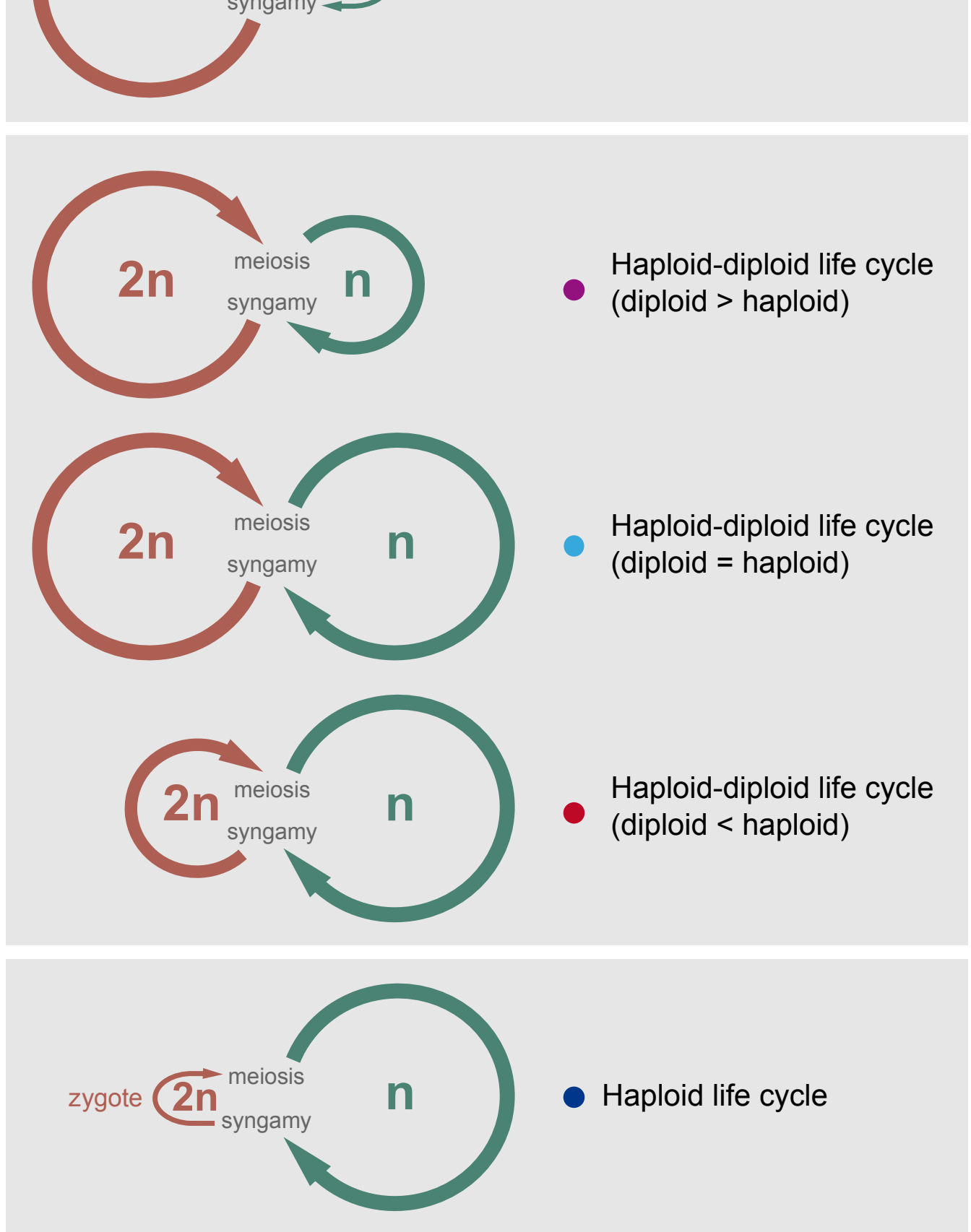
Haploid-diploid life cycle (haploid > diploid)

Haploid-diploid life cycle (diploid = haploid)

- Haploid-diploid life cycle (diploid > haploid)

Diploid life cycle

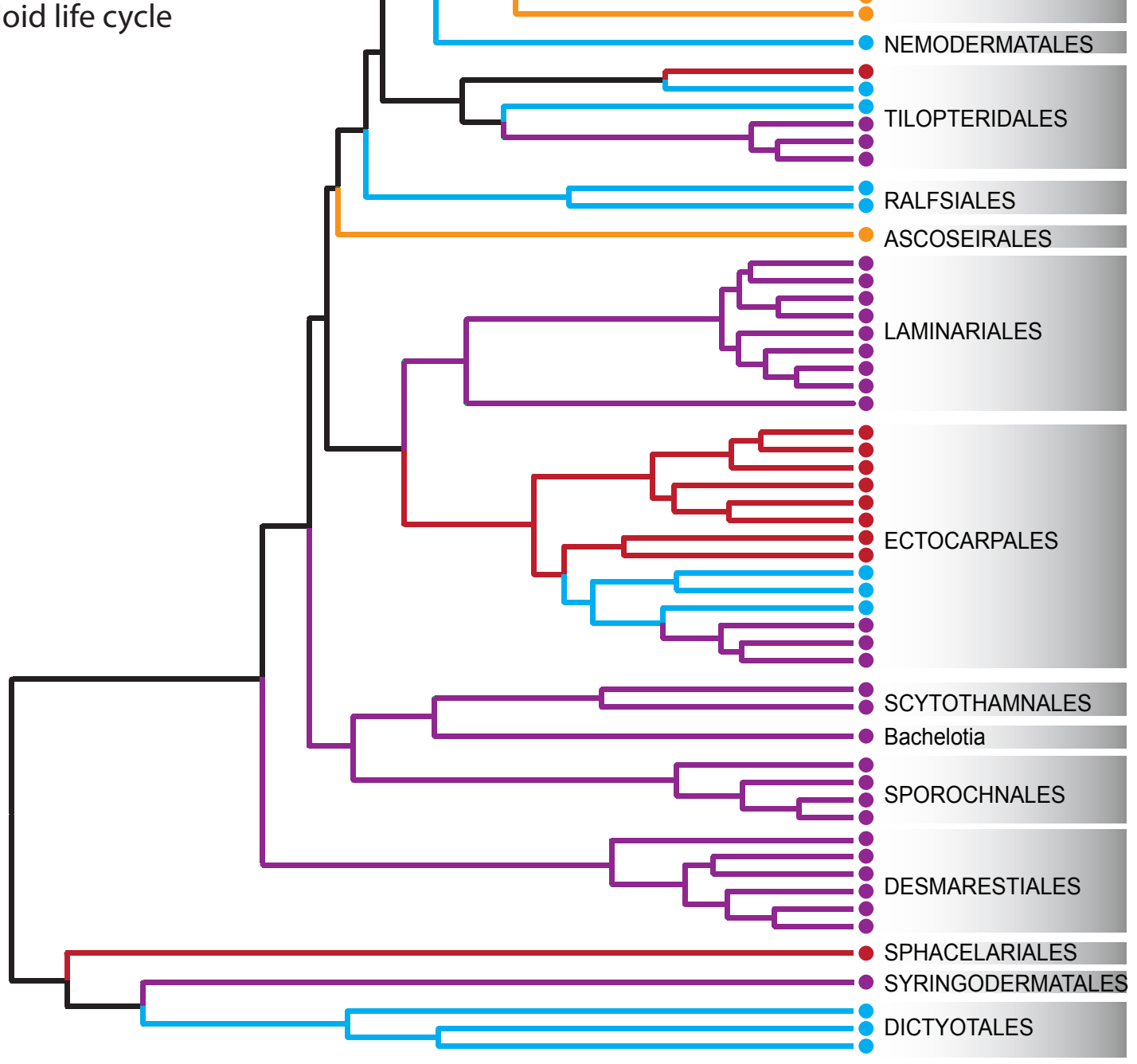

